\title{
Association of surgical margins with local recurrence in patients undergoing breast- conserving surgery after neoadjuvant chemotherapy
}

Joseph Lin

Changhua Christian Medical Foundation Changhua Christian Hospital

\section{Sam Li-Sheng Chen}

Taipei Medical University

Dar-Ren Chen ( $\nabla$ darren_chen@cch.org.tw )

Changhua Christian Medical Foundation Changhua Christian Hospital https://orcid.org/0000-00020897-4374

\section{Kuo-Juei Lin}

E-Da Hospital

\section{Yu-Fen Wang}

Changhua Christian Medical Foundation Changhua Christian Hospital

\section{Ling-Hui Huang}

Changhua Christian Medical Foundation Changhua Christian Hospital

\section{Research article}

Keywords: Neoadjuvant, Breast-conserving surgery, Surgical margin, Recurrence

Posted Date: March 13th, 2020

DOl: https://doi.org/10.21203/rs.3.rs-17122/v1

License: (9) This work is licensed under a Creative Commons Attribution 4.0 International License. Read Full License

Version of Record: A version of this preprint was published at BMC Cancer on May 20th, 2020. See the published version at https://doi.org/10.1186/s12885-020-06955-6. 


\section{Abstract}

Background The aim of the current study was to report a single-institution experience using breastconserving surgery after neoadjuvant chemotherapy (NACT), focusing on the association between microscopic resection margin status and locoregional recurrence (LRR). Methods Our institutional prospectively maintained database was reviewed to identify patients who were treated with NACT between January 2008 and April 2018. Results Among the main partial mastectomy specimens available for analysis $(n=161), 28$ had margins $<1 \mathrm{~mm}, 21$ had margin width of $1-2 \mathrm{~mm}$ and the remaining 112 had margins $>2 \mathrm{~mm}$. LRR occurred in 16 patients $(9.9 \%)$ and distant metastases were detected in 27 $(16.8 \%)$ patients. There was no significant difference in the LRR between the $>2 \mathrm{~mm}$ margin group with a 60 -month cumulative survival of $85.2 \%$ compared with $76.2 \%$ for the $\leq 2 \mathrm{~mm}$ group $(P=0.335)$ in the Kaplan-Meier analysis. When we stratified patients by margin widths of $\geq 1 \mathrm{~mm}$ or $<1 \mathrm{~mm}$, there was no LRR-free survival benefit observed for the $\geq 1 \mathrm{~mm}$ pathologic excision margin group in the univariate analysis (hazard ratio $=0.443 ; 95 \%$ confidence interval $=0.142-1.383 ; \mathrm{P}=0.161$ ) with a 60 -month cumulative LRR-free survival of $84.9 \%$ compared with $69.5 \%$ for the $<1 \mathrm{~mm}$ margin cohort $(P=0.150)$. Conclusions In the absence of multiple scattered microscopic tumour foci, a negative margin of no ink on tumour maybe sufficient for stage I-III invasive breast cancer treated with NACT and breast-conserving surgery.

\section{Background}

Despite the lack of overall survival benefits, the use of neoadjuvant chemotherapy (NACT) in early-stage breast cancer nonetheless manifests other advantages; as such, it converts patients into applicants for breast-conserving surgery (BCS) after lowering tumour volumes and reduces the use of axillary lymph node dissection [1, 2]. Moreover, it allows the assessment of therapeutic response to a distinct chemotherapy regimen. The ultimate goals of BCS are complete removal of the breast tumour with adequate margins and simultaneous preservation of the natural shape of the breast [3]. Studies have demonstrated that a "no ink on tumour" lumpectomy margin is adequate for invasive breast cancer treated with BCS followed by whole-breast radiation [4, 5], but those patients display higher locoregional recurrence (LRR) rates than mastectomy patients [6]. Despite the increasing evidence demonstrating the feasibility of BCS after NACT [7], the combined use of NACT and BCS has certainly drawn concerns of high LRR in patients with locally advanced breast cancer as reported by several studies [8-10]. Furthermore, increased pathological complete response ( $\mathrm{pCR}$ ) rates with the use of newer therapeutic agents which was not translated into a higher rate of BCS may have attributed to the distraction in relation to the adequate margin on BCS after NACT [11]. The risk of LRR after BCS could be influenced by factors related to therapeutic strategies, tumour subtypes and surgical margin status. Negative margins reduce the risk of local recurrence, but to date, there is no consensus on what constitutes an adequate negative margin in BCS after NACT. The aim of the current study was to report a single-institution experience using BCS after NACT, focusing on the association between microscopic resection margin 
status and LRR, as this information can be crucial in improving surgical options after NACT considering the risks and potential benefits in this setting.

\section{Methods}

This study obtained approval from the Changhua Christian Hospital. In this study, patients with breast cancer receiving NACT from January 2008 to April 2018 were enrolled. Initial diagnosis of breast cancer was made through core needle biopsy with ultrasound guidance, through which information on receptor status was obtained using immunohistochemical staining. Disease stage was classified based on the 2010 staging system of the American Joint Committee of Cancer (AJCC) TNM criteria.

Information on Ki-67 expression in pre-therapeutic core needle biopsies was not available until 2018 at our hospital, and histology grade was used as an alternative measurement to determine proliferation activity. Intrinsic subtypes were therefore determined as follows: luminal (ER + and/or progesterone receptor (PR) +, HER2-, all grades), luminal HER2 (ER + and/or PR+, HER2+, all grades), HER2-type (ER-, $\mathrm{PR}-$ and HER2 + ) and triple negative (ER-, PR- and HER2-) $[12,13]$.

Imaging examinations to assess breast and lymph nodes included ultrasonography, mammography and magnetic resonance imaging (MRI); the largest dimension recorded from these examinations was defined as the tumour size. Indications for BCS remained homogenous during the study period: absence of multicentric disease or extensive microcalcification, lack of chest wall or skin involvement and predictable sufficiency of breast volume after BCS. Partial mastectomy specimens were sent to surgical pathologists for microscopic assessment. All patients underwent whole-breast radiation therapy for a total dose of $5000 \mathrm{cGY}$ given in 25-28 fractions with or without a boost to the primary tumour site. Both pre-NACT and post-NACT tumour size were determined by imaging (either MRI or ultrasonography). Our institutional definition of $\mathrm{PCR}$ was eradication of invasive cancer and in-situ cancer in the breast and axillary (ypT0 ypN0), which was consistent with the meta-analysis of Cortazar et al. [14]

Histological variants of breast carcinoma were classified into the following subtypes: (1) infiltrating ductal carcinoma (IDC), (2) infiltrating lobular carcinoma (ILC), (3) IDC + ductal carcinoma in situ (DCIS) (DCIS component >10\%), (4) ILC + lobular carcinoma in situ (LCIS) (LCIS component > 10\%), (5) IDC + ILC or (6) others (mucinous, medullary, etc.). Primary tumour response to NACT was monitored by ultrasonography after each cycle of chemotherapy, and for tumours that have progressively decreased in size, an ultrasound-guided metallic marker insertion was done for future localisation.

All specimens were oriented with sutures, dye-inked followed by sectioning at 3- to 5-mm intervals, and the smallest distance between the tumour edge and an inked normal tissue margin was measured using an ocular micrometre (to the nearest $1 \mathrm{~mm}$ if $>2 \mathrm{~mm}$ distance or to the nearest $0.1 \mathrm{~mm}$ if $<2 \mathrm{~mm}$ ). An involved margin was defined as invasive disease at the inked resection margin, whereas uninvolved margins were classified microscopically and reported within a specified distance (>2 mm, 1-2 $\mathrm{mm}$ and < $1 \mathrm{~mm}$ ) of the resection margin. 
The primary outcome of interest was any LRR that was defined as recurrence tumour in the ipsilateral breast parenchyma or metastatic disease in the internal mammary, ipsilateral axillary, infraclavicular or supraclavicular nodes [15]. Secondary outcomes included event-free survival (free of LRR, distant metastasis and death). Time to event was defined as the interval from the definite surgery and the date of the first recurrence.

Clinicopathological characteristics were compared by Mann-Whitney $U$ test for medians and chi-square test for proportions. Kaplan-Meier (KM) survival curves were generated to compare the survival outcomes according to the margin status and the use of MRI [16], and two-sided log rank test was used to test the significant difference between survival experiences [17]. Statistical analysis was performed using MedCalc statistical software version 18.5 (MedCalc Software bvba, Ostend, Belgium), and a significance level of $5 \%$ was used in all analyses.

\section{Results}

A total of 555 cases were identified, but 127 were excluded because of the following reasons: stage IV breast cancer $(n=65)$, bilateral breast cancer $(n=12)$, lost to follow-up $(n=13)$, expired without surgery ( $n$ $=10)$ and on-going NACT $(n=27)$. Of the remaining 428 patients, 172 patients $(40.2 \%)$ had undergone BCS with radiotherapy and 256 (59.8\%) underwent mastectomy (Fig. 1). Of the 172 BCS patients, 11 had involved margin based on pathological examination, and this left us with 161 patients for analysis.

The median age of the studied population was 47.4 years (range 25.4-87.3); 65 (40.4\%) patients aged $\geq$ 50 years and $96(50.6 \%)$ patients aged $<50$ years. NACT comprised of $4-6$ courses of anthracyclinebased $(n=33,20.5 \%)$, taxane-based $(n=14,8.7 \%)$, combined anthracycline-taxane-based $(n=65,40.4 \%)$ and HER2-targeted agents added regimens $(n=46,28.6 \%)$. IDC represented $145(90.1 \%)$ of all patients, which was considered the most common histopathological type in this study. Statistical associations between the three margin groups and tumour characteristics are summarised in Table 1. 
Table 1

Patient characteristics $(n=161)$

Surgical margin

Characteristics

$\begin{array}{lllll}\text { All } & <1 \mathrm{~mm} & \geq 1 \mathrm{~mm},< & \geq 2 \mathrm{~mm} & P \\ \left(\begin{array}{l}n=161) \\ (\%)\end{array}\right. & \begin{array}{l}(\mathrm{n}=28) \\ (\%)\end{array} & \begin{array}{l}2 \mathrm{~mm} \\ (\mathrm{n}=21)(\%)\end{array} & \begin{array}{l}(\mathrm{n}=112) \\ (\%)\end{array} & P\end{array}$

Age, year

Median (range)

47.4

(25.4-

87.3)

Mean \pm SD

$<50$

$\geq 50$

Tumor size

$\mathrm{T} 1(\leq 2 \mathrm{~cm})$

T2 $(>2 \mathrm{~cm}, \leq 5 \mathrm{~cm})$

T3 $(>5 \mathrm{~cm})$

Lymph node status

Negative

Positive

Histological type

IDC

$\mathrm{IDC}+\mathrm{DCIS}$

Others

Histological grade

$\begin{array}{llllll}\text { in situ } & 2(1.3) & 1(3.6) & 1(5.0) & 0(0) & 0.173 \\ \text { I } & 17(11.3) & 4(14.3) & 1(5.0) & 12(11.8) & \\ \text { II } & 77(51.3) & 16(57.1) & 13(65.0) & 48(47.1) \\ \text { III } & 54(36.0) & 7(25.0) & 5(25.0) & 42(41.2) \\ \text { Missing } & 11 & 0 & 1 & 10\end{array}$

$\begin{array}{lllll}18(11.2) & 3(10.7) & 1(4.8) & 14(12.5) & 0.782 \\ 132(82.0) & 24(85.7) & 18(85.7) & 90(80.4) & \\ 11(6.8) & 1(3.6) & 2(9.5) & 8(7.1) & \end{array}$

$\begin{array}{lllll}34(21.1) & 6(21.4) & 5(23.8) & 23(20.5) & 0.944 \\ 127(78.9) & 22(78.6) & 16(76.2) & 89(79.5) & \end{array}$

\begin{tabular}{lllll}
$145(90.1)$ & $22(78.6)$ & $19(90.5)$ & $104(92.9)$ & 0.152 \\
\hline $12(7.5)$ & $4(14.3)$ & $1(4.8)$ & $7(6.2)$ & \\
$4(2.5)$ & $2(7.1)$ & $1(4.8)$ & $1(0.9)$ &
\end{tabular}

$\begin{array}{lll}51.7 & 46.4 & 46.9 \\ (27.6- & (25.4-68.5) & (27.6- \\ 87.3) & & 74.7)\end{array}$

$48.1 \pm 11.0 \quad 51.7 \pm \quad 46.3 \pm 10.1 \quad 47.5 \pm 10.4$

$96(59.6) \quad 13(46.4) \quad 12(57.1)$

$71(63.4)$

0.254

$65(40.4) \quad 15(53.6) \quad 9(42.9)$

$41(36.6)$ 


\section{Surgical margin}

\begin{tabular}{|c|c|c|c|c|c|}
\hline Luminal & $53(32.9)$ & $9(32.1)$ & $11(52.4)$ & $33(29.5)$ & 0.379 \\
\hline Luminal HER2 & $41(25.5)$ & $8(28.6)$ & $3(14.3)$ & $30(26.8)$ & \\
\hline HER2 & $21(13.0)$ & 5 (17.9) & $3(14.3)$ & $13(11.6)$ & \\
\hline TNBC & $46(28.6)$ & $6(21.4)$ & $4(19.0)$ & $36(32.1)$ & \\
\hline \multicolumn{6}{|l|}{ Chemotherapy } \\
\hline Anthracycline-based & $33(20.5)$ & $5(17.9)$ & 7 (33.3) & $21(18.8)$ & 0.427 \\
\hline Taxane-based & $14(8.7)$ & $2(7.1)$ & $2(9.5)$ & $10(8.9)$ & \\
\hline $\begin{array}{l}\text { Combined anthracycline and } \\
\text { taxane }\end{array}$ & $6540.4)$ & $10(35.7)$ & 7 (33.3) & $48(42.9)$ & \\
\hline $\begin{array}{l}\text { HER2 targeting agent } \\
\text { contained }\end{array}$ & $46(28.6)$ & $9(32.1)$ & $5(23.8)$ & $32(28.6)$ & \\
\hline Others & $3(1.9)$ & $2(7.1)$ & $0(0)$ & $1(0.9)$ & \\
\hline \multicolumn{6}{|l|}{ Follow-up, month } \\
\hline Median (range) & $\begin{array}{l}34.7 \\
(5.3- \\
118.9)\end{array}$ & $\begin{array}{l}23.5 \\
(5.3- \\
105.5)\end{array}$ & $\begin{array}{l}39.3 \\
(7.7-105.6)\end{array}$ & $\begin{array}{l}35.8 \\
(6.9- \\
118.9)\end{array}$ & \\
\hline Mean \pm SD & $44.9 \pm 31.8$ & $\begin{array}{l}36.1 \pm \\
29.5\end{array}$ & $49.3 \pm 34.2$ & $46.2 \pm 31.9$ & \\
\hline
\end{tabular}

Regarding histological grading, 17 cases (11.3\%) were grade I, 77 cases (51.3\%) were grade II, 54 cases (36\%) were grade III and 11 cases did not have grade status. Luminal subtype represented $53(32.9 \%)$ of all patients, triple negative, luminal HER2 and HER2 subtypes represented 46 (28.6\%), 41 (25.5\%) and 21 (13\%) of all BCS patients, respectively. The median follow-up time was 47 months (range 25-87). Thirtyeight patients $(22.1 \%)$ achieved a pCR; overall pCR was $8.9 \%(5 / 56)$ in luminal subtype patients, $18.2 \%$ (8/44) in luminal HER2 subtype patients, 50\% (12/24) in HER2 subtype patients and $27.1 \%(13 / 48)$ in triple negative breast cancer (TNBC) patients. Their pCR rates according to molecular subtypes are shown in Fig. 2.

Among the main partial mastectomy specimens available for analysis $(n=161), 28$ had margins $<1 \mathrm{~mm}$, 21 had margin width of 1-2 $\mathrm{mm}$ and the remaining 112 had margins $>2 \mathrm{~mm}$. Involved margins were reported in seven patients, and all of them underwent re-excision to obtain negative margins. Overall, LRR occurred in 16 patients (9.9\%) and distant metastases were detected in $27(16.8 \%)$ patients. Of these patients with LRR, an in-breast recurrence developed in 10 patients, five patients had nodal failure and one patient exhibited two sites of LRR simultaneously. 
There were $4(4 / 28,14.3 \%)$ LRR events in the $<1 \mathrm{~mm}$ margin cohort, $2(2 / 21,9.5 \%)$ in the $1-2 \mathrm{~mm}$ group and $10(10 / 112,8.9 \%)$ in the $>2 \mathrm{~mm}$ group. There was no significant difference in the LRR between the > $2 \mathrm{~mm}$ margin group with a 60 -month cumulative survival of $85.2 \%$ compared with $76.2 \%$ for the $\leq 2 \mathrm{~mm}$ group ( $P=0.335$; Fig. 3.a) in the KM analysis. When we stratified patients by margin widths of $\geq 1 \mathrm{~mm}$ or $<1 \mathrm{~mm}$, there was no LRR-free survival benefit observed for the $\geq 1 \mathrm{~mm}$ pathologic excision margin group in the univariate analysis (hazard ratio $=0.443 ; 95 \%$ confidence interval $=0.142-1.383 ; \mathrm{P}=0.161$ ) (Table 2) with a 60 -month cumulative LRR-free survival of $84.9 \%$ compared with $69.5 \%$ for the $<1 \mathrm{~mm}$ margin cohort ( $P=0.150 ;$ Fig. 3.b). In the survival analysis for event-free survival, there was no significant difference for margins $>2 \mathrm{~mm}$ versus $\leq 2 \mathrm{~mm}$ and no difference for $\geq 1 \mathrm{~mm}$ versus $<1 \mathrm{~mm}$ (Fig. 3.c-d).

Table 2

Univariate logistic regression analysis of LRR-free survival and event-free survival

\begin{tabular}{|c|c|c|c|c|c|c|}
\hline \multirow[b]{2}{*}{ Variables } & \multicolumn{3}{|c|}{ LRR-free survival } & \multicolumn{3}{|c|}{ Event-free survival } \\
\hline & $\begin{array}{l}\text { Hazard } \\
\text { ratio }\end{array}$ & $\begin{array}{l}95 \% \\
\text { confidence } \\
\text { interval }\end{array}$ & $P$ & $\begin{array}{l}\text { Hazard } \\
\text { ratio }\end{array}$ & $\begin{array}{l}95 \% \\
\text { confidence } \\
\text { interval }\end{array}$ & $P$ \\
\hline $\begin{array}{l}\text { Age, years } \\
(\geq 50 \text { vs. }<50)\end{array}$ & 1.013 & $0.368-2.789$ & 0.980 & 0.856 & $0.413-1.775$ & 0.676 \\
\hline $\begin{array}{l}\text { Tumor size, cm } \\
(>2 \text { vs. } \leq 2)\end{array}$ & 1.270 & $0.167-9.637$ & 0.817 & 0.815 & $0.247-2.686$ & 0.737 \\
\hline $\begin{array}{l}\text { Lymph node } \\
\text { (positive vs. } \\
\text { negative) }\end{array}$ & 2.682 & $0.609-11.811$ & 0.192 & 1.972 & $0.757-5.135$ & 0.164 \\
\hline $\begin{array}{l}\text { Histological } \\
\text { grade } \\
\text { (3 vs. } 0-2)\end{array}$ & 0.851 & $0.295-2.453$ & 0.766 & 1.098 & $0.520-2.316$ & 0.807 \\
\hline $\begin{array}{l}\text { ER } \\
\text { (positive vs. } \\
\text { negative) }\end{array}$ & 0.927 & $0.334-2.574$ & 0.884 & 0.884 & $0.435-1.797$ & 0.734 \\
\hline $\begin{array}{l}\text { PR } \\
\text { (positive vs. } \\
\text { negative) }\end{array}$ & 0.977 & $0.362-2.633$ & 0.963 & 0.926 & $0.456-1.881$ & 0.832 \\
\hline $\begin{array}{l}\text { HER2 } \\
\text { (positive vs. } \\
\text { negative) }\end{array}$ & 1.555 & $0.583-4.146$ & 0.378 & 1.174 & $0.583-2.361$ & 0.654 \\
\hline $\begin{array}{l}\text { Ki-67 labelling } \\
\text { index, \% } \\
(\geq 14 \text { vs. < 14) }\end{array}$ & 3.253 & $0.688-15.388$ & 0.137 & 1.950 & $0.756-5.034$ & 0.167 \\
\hline $\begin{array}{l}\text { Surgical margin, } \\
\mathrm{mm} \\
(\geq 1 \text { vs. }<1)\end{array}$ & 0.443 & $0.142-1.383$ & 0.161 & 0.554 & $0.239-1.284$ & 0.169 \\
\hline
\end{tabular}


The logistic regression analysis analyses included age, lymph node status (positive vs. negative), histological grade, receptor status, Ki-67 index, pCR status and surgical margin distance. On the univariate analyses, these variables are independent of LRR-free survival and event-free survival (Table 2). Only lymph node status was found to be a significant predictor of event-free survival (hazard ratio $=3.374 ; 95 \%$ confidence interval $=1.020-11.155 ; \mathrm{P}=0.046$ ) on multivariate analysis.

\section{Discussion}

The introduction of target therapy and advancement of chemotherapeutic treatments have brought an increase in PCR rates, but BCS rates following NACT stay relatively unaffected [11], partly because an increase number of patients may opt for mastectomy treatments due to a lack of consensus on adequate margin in BCS after NACT. These findings may reflect discrepancies in practice among clinicians and guidelines with the consequence of re-excision to gain wider margins. In the present study, 428 women with untreated operable breast cancer received NACT from January 2008 to April 2018; 40.2\% $(n=172)$ of them underwent BCS and the remaining $59.8 \%(n=256)$ had mastectomy. In the present study, the overall BCS rate of $40.2 \%$ for patients was lower than that of $49.4 \%$ in the surgery first cohort from our previous study [18] despite comparable pCR rates of $22.1 \%$ with other studies $[19,20]$. This may have resulted from the higher LRR after BCS in patients who were treated with NACT [8-10], as one of our senior surgeons who performed more than half of the analysed BCS cases in this study had a BCS rate of $56 \%$. This variation between surgeons in clinical practices further lends credence to the consensus on a safe margin width in this patient population.

In our institution, diagnostic ultrasonography was performed by the operating surgeons after each cycle of NACT to evaluate tumour size and therapeutic response. Further, a metallic marker was only inserted in tumours that had progressively decreased in size for future localisation. Therefore, we have a lower rate of wire localisation due to an extensive usage of breast ultrasonography, and this low rate does not reflect the simplicity in choosing the optimal resected volume for complete tumour excision while preserving the cosmetic integrity of the breast. Moreover, most patients in this cohort underwent MRI before and after NACT, and this may give additional information in estimation of disease burden during the surgery as other studies suggested [21-23].

Volder et al. [24] reported an involved margin rate of $24.3 \%$ in patients who received NACT and BCS, with additional $17.7 \%$ of patients with close $(\leq 1 \mathrm{~mm})$ margin width identified in a nationwide pathologic study. Differences in therapeutic approaches among hospitals may have contributed to the high-observed margin rate $(24.3 \%)$ in this population-based study. Others reported a lower rate of re-excision in primary chemotherapy. Christy et al. [25] demonstrated that preoperative chemotherapy resulted in a significantly higher incidence of negative margins ( $90 \%$ vs. $55 \%$; $\mathrm{P}<0.01)$ and a lower re-excision rate $(6 \%$ vs. $37 \%$; $\mathrm{P}$ 0.01 ) compared with primary surgery. Karanlik et al. [26] reported that NACT was more likely to have negative margins ( $95 \%$ vs. $84 \% ; P=0.02)$ and less likely receive re-excision ( $4 \%$ vs. $8 \% ; P=0.02)$ as well. 
Our study also reported a low re-excision rate, re-excision surgery was given in $4.1 \%(7 / 172)$ of patients, and these seven patients all had an involved margin at the first place. Additional $14.5 \%(25 / 172)$ of patients with margin $<1 \mathrm{~mm}$ would have added to this re-excision rate $(4.1+14.5=18.6 \%)$ if $<1 \mathrm{~mm}$ margin width was considered positive. The lower re-excision rate did not however bring a higher recurrence rate. Moreover, 16 patients $(9.9 \%, 16 / 161)$ experienced LRR and 10 of them had breast-only local recurrence $(6.2 \%, 10 / 161)$ during the follow-up. Our results were comparable to Mittendorf et al. [27] who reported 5- and 10 -years LRR of $7 \%$ and $10 \%$, respectively. Our low re-excision rate did not correlate with a higher recurrence rate, and it was further supported by our multivariate analysis that failed to show the association between LRR and margin distance.

A few studies assessed the margin distance and outcomes in patients treated with BCS following NACT, and the results have been inconsistent. Chen et al. [19] reported on 340 cases treated at MD Anderson Cancer Centre between 1987 and 2000 and discovered no association between 5-year LRR-free survival and margin distances ( $>2 \mathrm{~mm}$ vs. $\leq 2 \mathrm{~mm}$ ). LRR and ipsilateral breast tumour recurrence were correlated with advanced nodal involvement, residual tumour $>2 \mathrm{~cm}$, multifocal residual disease and lymphovascular space invasion. In contrast, the Institute Curie reported that an increased ipsilateral breast tumour recurrence was associated with margins $\leq 2 \mathrm{~mm}$ in addition to clinical tumour $>2 \mathrm{~cm}$, age $<40$ and S-phase fraction $>4 \%$ [10]. The latest study by Choi et al. [20] on 382 patients showed no association between margin width and local recurrence but rather related to intrinsic subtypes, lack of pCR and positive nodal status. Factors such as age, tumour size, lymph node status, surgical margin, histological grade, Ki-67 index and receptor status were not found to be significant predictors of LRR on univariate analysis in our study. This might have been attributed to our population size due to its insufficient power to detect a difference. However, the low LRR in the present study suggests that even though a statistically significant difference may be achieved by increasing the sample size, this difference may not be translated into a clinically meaningful consequence in the real world.

The rates of pCR were highest in HER2 subtype patients (ER-, PR- and HER2+) with $50 \%$ followed by TNBC group with $27.1 \%$ in our study. While further analysis on pCR and prognosis stratified by subtypes would be statistically underpowered because of small sample size in our analysis, von Minckwitz in his meta-analysis of 6377 patients treated with NACT and BCS showed different prognosis among pCR patients stratified by subtypes [13]. They reported that PCR was associated with improved disease-free survival in luminal B/HER2 negative, HER2 and TNBC subtypes but not in luminal A or luminal HER2 breast cancer. This may suggest the importance of biologic characteristics of a tumour in achieving local control of breast cancer and the complete resection of the primary tumour may not be essential.

SSO-ASTRO introduced guidelines that suggested "no ink on tumour" as adequate margins for women with invasive breast cancer undergoing BCS, but this analysis did not include patients treated with NACT [4]. The purpose of the current study was to compare margin widths of $>2 \mathrm{~mm}, 1-2 \mathrm{~mm}$ and $<1 \mathrm{~mm}$ in NACT patients after BCS and their association with recurrence rate. Our results did not support the idea that $\geq 1 \mathrm{~mm}$ margins would decrease LRR, and it is important because it may reduce additional costs and psychological effect by minimising the need for re-excision [28]. 
This study had a few limitations. First, this was a retrospective, single-institution study with a comparatively small sample size. Second, the enrolled patients were given different chemotherapy regimens based on the tumour subtype. Additionally, patients with HER2 subtype were underrepresented and it might limit the generalisability of the results. However, this study benefits from its real-world clinical data and a relative standardised strategy to surgical approach and to margin assessment procedure. Further studies with greater sample sizes are necessary to determine the safe surgical margin with NACT and BCS.

\section{Conclusion}

This study has shown no increase in LRR for surgical margins $<1 \mathrm{~mm}$ compared with margins $\geq 1 \mathrm{~mm}$. In the absence of multiple scattered microscopic tumour foci, a negative margin of no ink on tumour maybe sufficient for stage I-III invasive breast cancer treated with NACT and BCS, and it is not necessary for re-excision if surgical width is $<1 \mathrm{~mm}$.

\section{List Of Abbreviations}

NACT, neoadjuvant chemotherapy; BCS, breast-conserving surgery; LRR, locoregional recurrence; pCR, pathological complete response; AJCC, American Joint Committee of Cancer; PR, progesterone receptor; MRI, magnetic resonance imaging; IDC, infiltrating ductal carcinoma; DCIS, ductal carcinoma in situ; ILC, infiltrating lobular carcinoma; LCIS, lobular carcinoma in situ; TNBC, triple negative breast cancer

\section{Declarations}

\section{Ethics approval and consent to participate}

Prior to collecting clinical data from the patient's medical record, a written informed consent was obtained from her. The study protocol was approved by the Institutional Review Board of Changhua Christian Hospital, Taiwan. All methods were carried out in accordance with the Declaration of Helsinki.

\section{Consent for publication}

Not applicable.

\section{Availability of data and materials}

All datasets used or analysed for this study are available from the corresponding author upon reasonable request.

\section{Competing interests}

The authors declare that there are no conflicts of interest relevant to the content of this manuscript. 


\section{Funding}

The authors have received no funding for this study.

\section{Authors' contributions}

The study was designed by DRC. Clinical data acquisition and analysis were performed by JL, DRC, KJL, YFW and LHH. Statistical analyses were performed by JL, SLSC and YFW. The manuscript was written by JL, DRC and YFW. All authors read and approved the manuscript.

\section{Acknowledgements}

We would like to thank Ms. Hung-Ting Lin, Ms. Yun-Cen Chen and Mr. Yung-Liang Yeh for their administrative and technical assistance.

\section{References}

1. Fisher B, Brown A, Mamounas E, Wieand S, Robidoux A, Margolese RG, Cruz AB, Jr., Fisher ER, Wickerham DL, Wolmark N, DeCillis A, Hoehn JL, Lees AW, Dimitrov NV. Effect of preoperative chemotherapy on local-regional disease in women with operable breast cancer: findings from National Surgical Adjuvant Breast and Bowel Project B-18. J Clin Oncol. 1997; 15(7):2483-93.

2. van der Hage JA, van de Velde CJ, Julien JP, Tubiana-Hulin M, Vandervelden C, Duchateau L. Preoperative chemotherapy in primary operable breast cancer: results from the European Organization for Research and Treatment of Cancer trial 10902. J Clin Oncol. 2001; 19(22):4224-37.

3. Lin J, Chen DR, Wang YF, Lai HW. Oncoplastic Surgery for Upper/Upper Inner Quadrant Breast Cancer. PLoS One. 2016; 11(12):e0168434.

4. Moran MS, Schnitt SJ, Giuliano AE, Harris JR, Khan SA, Horton J, Klimberg S, Chavez-MacGregor M, Freedman G, Houssami N, Johnson PL, Morrow M, Society of Surgical O, American Society for Radiation O. Society of Surgical Oncology-American Society for Radiation Oncology consensus guideline on margins for breast-conserving surgery with whole-breast irradiation in stages I and II invasive breast cancer. J Clin Oncol. 2014; 32(14):1507-15.

5. Houssami N, Macaskill P, Marinovich ML, Morrow M. The association of surgical margins and local recurrence in women with early-stage invasive breast cancer treated with breast-conserving therapy: a meta-analysis. Ann Surg Oncol. 2014; 21(3):717-30.

6. Clarke M, Collins R, Darby S, Davies C, Elphinstone P, Evans V, Godwin J, Gray R, Hicks C, James S, MacKinnon E, McGale P, McHugh T, Peto R, Taylor C, Wang Y, Early Breast Cancer Trialists' Collaborative G. Effects of radiotherapy and of differences in the extent of surgery for early breast cancer on local recurrence and 15-year survival: an overview of the randomised trials. Lancet. 2005; 366(9503):2087-106.

7. Mieog JS, van der Hage JA, van de Velde CJ. Neoadjuvant chemotherapy for operable breast cancer. Br J Surg. 2007; 94(10):1189-200. 
8. Calais G, Berger C, Descamps P, Chapet S, Reynaud-Bougnoux A, Body G, Bougnoux P, Lansac J, Le Floch 0 . Conservative treatment feasibility with induction chemotherapy, surgery, and radiotherapy for patients with breast carcinoma larger than $3 \mathrm{~cm}$. Cancer. 1994; 74(4):1283-8.

9. Mauriac L, MacGrogan G, Avril A, Durand M, Floquet A, Debled M, Dilhuydy JM, Bonichon F. Neoadjuvant chemotherapy for operable breast carcinoma larger than $3 \mathrm{~cm}$ : a unicentre randomized trial with a 124-month median follow-up. Institut Bergonie Bordeaux Groupe Sein (IBBGS). Ann Oncol. 1999; 10(1):47-52.

10. Rouzier R, Extra JM, Carton M, Falcou MC, Vincent-Salomon A, Fourquet A, Pouillart P, Bourstyn E. Primary chemotherapy for operable breast cancer: incidence and prognostic significance of ipsilateral breast tumor recurrence after breast-conserving surgery. J Clin Oncol. 2001; 19(18):382835.

11. Bear HD, Anderson S, Brown A, Smith R, Mamounas EP, Fisher B, Margolese R, Theoret H, Soran A, Wickerham DL, Wolmark N, National Surgical Adjuvant B, Bowel Project Protocol B. The effect on tumor response of adding sequential preoperative docetaxel to preoperative doxorubicin and cyclophosphamide: preliminary results from National Surgical Adjuvant Breast and Bowel Project Protocol B-27. J Clin Oncol. 2003; 21(22):4165-74.

12. Goldhirsch A, Wood WC, Coates AS, Gelber RD, Thurlimann B, Senn HJ, Panel m. Strategies for subtypes-dealing with the diversity of breast cancer: highlights of the St. Gallen International Expert Consensus on the Primary Therapy of Early Breast Cancer 2011. Ann Oncol. 2011; 22(8):1736-47.

13. von Minckwitz G, Untch M, Blohmer JU, Costa SD, Eidtmann H, Fasching PA, Gerber B, Eiermann W, Hilfrich J, Huober J, Jackisch C, Kaufmann M, Konecny GE, Denkert C, Nekljudova V, Mehta K, Loibl S. Definition and impact of pathologic complete response on prognosis after neoadjuvant chemotherapy in various intrinsic breast cancer subtypes. J Clin Oncol. 2012; 30(15):1796-804.

14. Cortazar P, Zhang L, Untch M, Mehta K, Costantino JP, Wolmark N, Bonnefoi H, Cameron D, Gianni L, Valagussa P, Swain SM, Prowell T, Loibl S, Wickerham DL, Bogaerts J, Baselga J, Perou C, Blumenthal G, Blohmer J, Mamounas EP, Bergh J, Semiglazov V, Justice R, Eidtmann H, Paik S, Piccart M, Sridhara R, Fasching PA, Slaets L, Tang S, Gerber B, Geyer CE, Jr., Pazdur R, Ditsch N, Rastogi P, Eiermann W, von Minckwitz G. Pathological complete response and long-term clinical benefit in breast cancer: the CTNeoBC pooled analysis. Lancet. 2014; 384(9938):164-72.

15. Wapnir IL, Anderson SJ, Mamounas EP, Geyer CE, Jr., Jeong JH, Tan-Chiu E, Fisher B, Wolmark N. Prognosis after ipsilateral breast tumor recurrence and locoregional recurrences in five National Surgical Adjuvant Breast and Bowel Project node-positive adjuvant breast cancer trials. J Clin Oncol. 2006; 24(13):2028-37.

16. Kaplan EL, Meier P. Nonparametric Estimation from Incomplete Observations. J Am Stat Assoc. 1958; 53(282):457-81.

17. Peto R, Pike MC, Armitage P, Breslow NE, Cox DR, Howard SV, Mantel N, McPherson K, Peto J, Smith PG. Design and analysis of randomized clinical trials requiring prolonged observation of each patient. II. analysis and examples. Br J Cancer. 1977; 35(1):1-39. 
18. Lai HW, Chen CJ, Lin YJ, Chen SL, Wu HK, Wu YT, Kuo SJ, Chen ST, Chen DR. Does Breast Magnetic Resonance Imaging Combined With Conventional Imaging Modalities Decrease the Rates of Surgical Margin Involvement and Reoperation?: A Case-Control Comparative Analysis. Medicine (Baltimore). 2016; 95(22):e3810.

19. Chen AM, Meric-Bernstam F, Hunt KK, Thames HD, Oswald MJ, Outlaw ED, Strom EA, McNeese MD, Kuerer HM, Ross MI, Singletary SE, Ames FC, Feig BW, Sahin AA, Perkins GH, Schechter NR, Hortobagyi GN, Buchholz TA. Breast conservation after neoadjuvant chemotherapy: the MD Anderson cancer center experience. J Clin Oncol. 2004; 22(12):2303-12.

20. Choi J, Laws A, Hu J, Barry W, Golshan M, King T. Margins in Breast-Conserving Surgery After Neoadjuvant Therapy. Ann Surg Oncol. 2018; 25(12):3541-7.

21. Fischer U, Kopka L, Grabbe E. Breast carcinoma: effect of preoperative contrast-enhanced MR imaging on the therapeutic approach. Radiology. 1999; 213(3):881-8.

22. Jochelson MS, Lampen-Sachar K, Gibbons G, Dang C, Lake D, Morris EA, Morrow M. Do MRI and mammography reliably identify candidates for breast conservation after neoadjuvant chemotherapy? Ann Surg Oncol. 2015; 22(5):1490-5.

23. Sung JS, Li J, Da Costa G, Patil S, Van Zee KJ, Dershaw DD, Morris EA. Preoperative breast MRI for early-stage breast cancer: effect on surgical and long-term outcomes. Am J Roentgenol. 2014; 202(6):1376-82.

24. Volders JH, Haloua MH, Krekel NM, Negenborn VL, Barbe E, Sietses C, Jozwiak K, Meijer S, van den Tol MP, the nationwide $n$, registry of $h$, cytopathology in the $N$. Neoadjuvant chemotherapy in breastconserving surgery - Consequences on margin status and excision volumes: A nationwide pathology study. Eur J Surg Oncol. 2016; 42(7):986-93.

25. Christy CJ, Thorsteinsson D, Grube BJ, Black D, Abu-Khalaf M, Chung GG, DiGiovanna MP, Miller K, Higgins SA, Weidhaas J, Harris L, Tavassoli FA, Lannin DR. Preoperative chemotherapy decreases the need for re-excision of breast cancers between 2 and 4 cm diameter. Ann Surg Oncol. 2009; 16(3):697-702.

26. Karanlik H, Ozgur I, Cabioglu N, Sen F, Erturk K, Kilic B, Onder S, Deniz M, Yavuz E, Aydiner A. Preoperative chemotherapy for T2 breast cancer is associated with improved surgical outcome. Eur $\mathrm{J}$ Surg Oncol. 2015; 41(9):1226-33.

27. Mittendorf EA, Buchholz TA, Tucker SL, Meric-Bernstam F, Kuerer HM, Gonzalez-Angulo AM, Bedrosian I, Babiera GV, Hoffman K, Yi M, Ross MI, Hortobagyi GN, Hunt KK. Impact of chemotherapy sequencing on local-regional failure risk in breast cancer patients undergoing breast-conserving therapy. Ann Surg. 2013; 257(2):173-9.

28. Al-Ghazal SK, Blamey RW, Stewart J, Morgan AA. The cosmetic outcome in early breast cancer treated with breast conservation. Eur J Surg Oncol. 1999; 25(6):566-70.

\section{Figures}




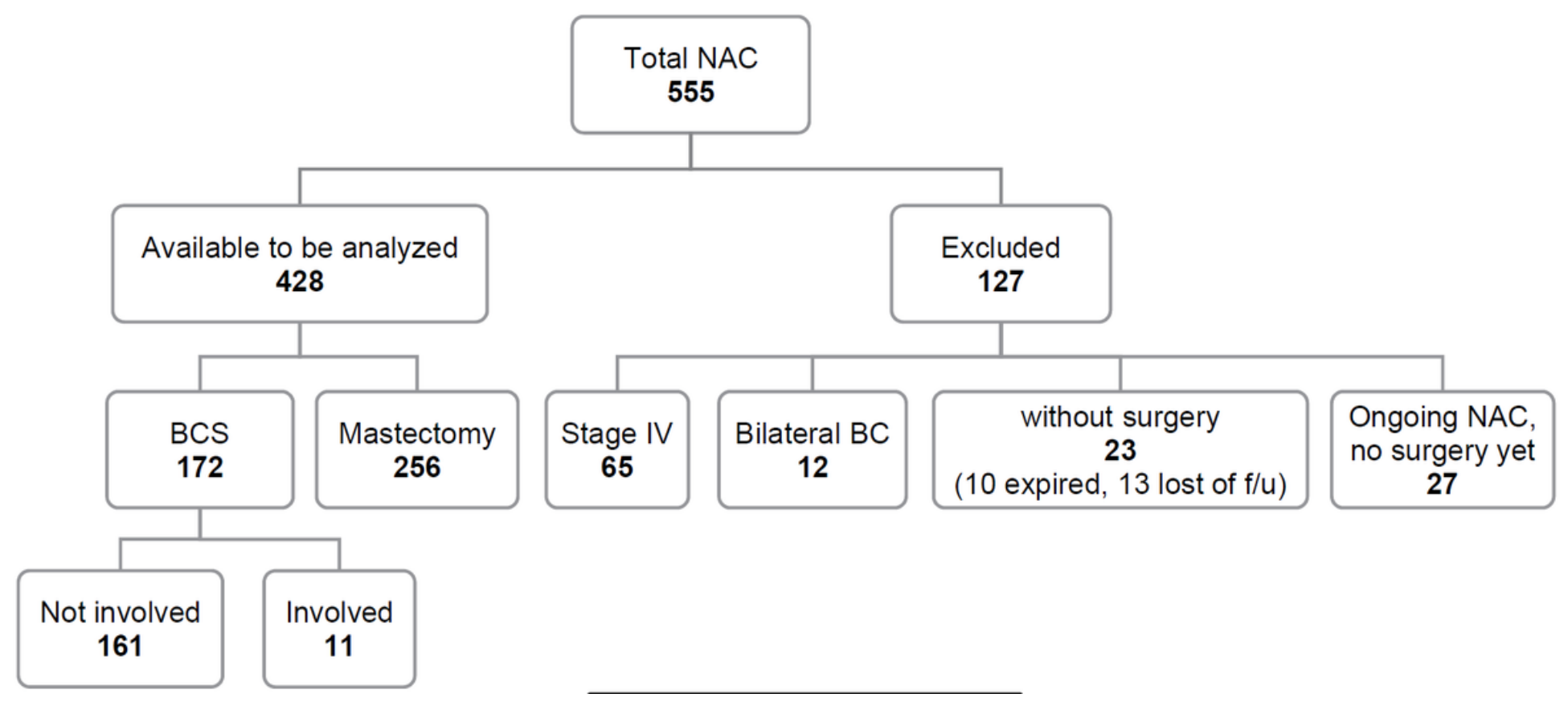

\section{Figure 1}

Flow chart of patients treated with NACT followed by surgical treatment. 


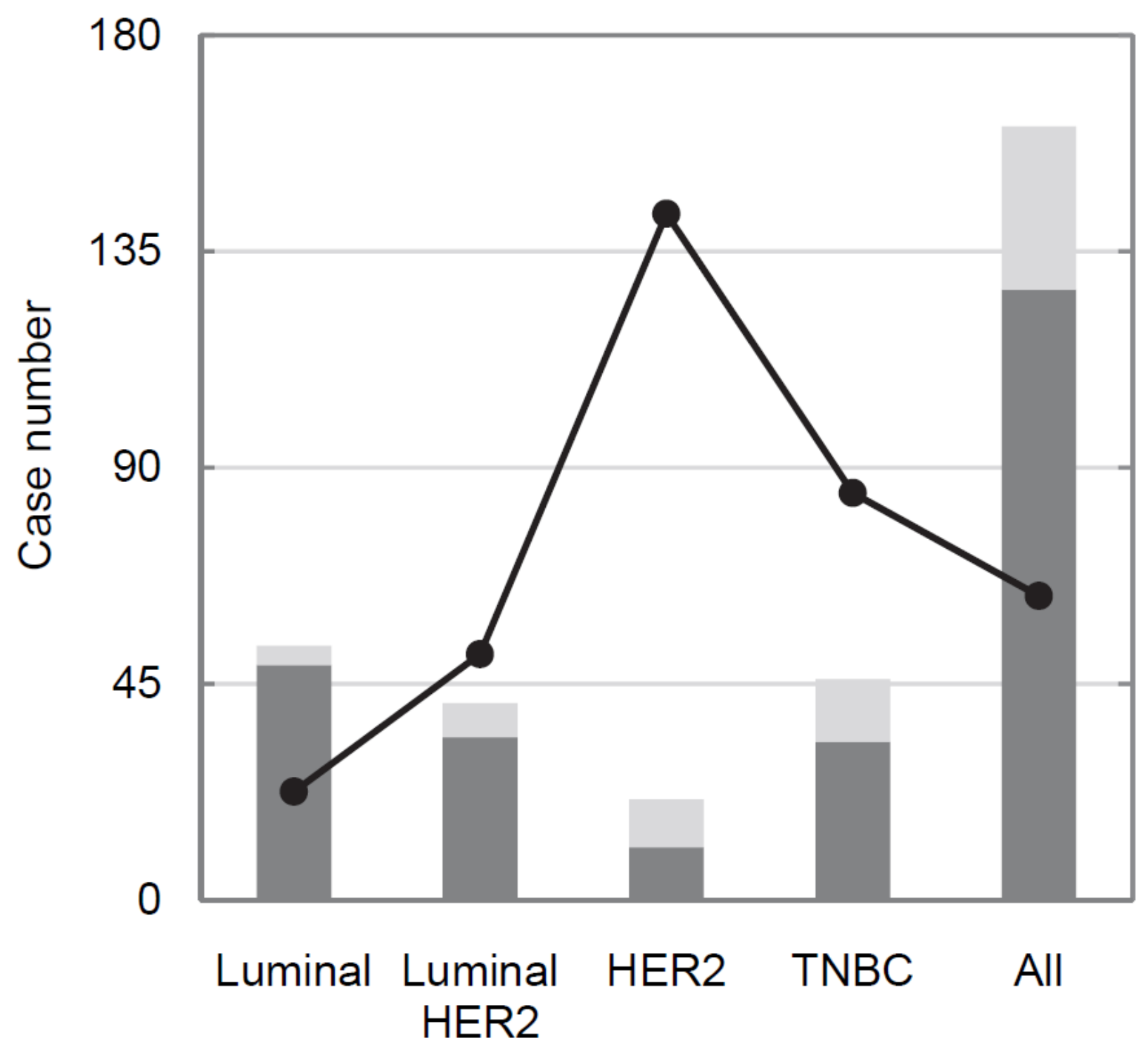

60.0

45.0

ฮำ

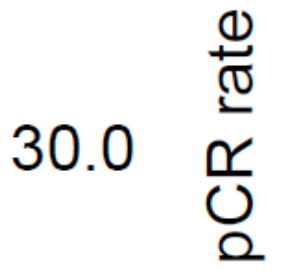

15.0

0.0

Figure 2

Complete pathologic response of NACT patients with BCS by molecular subtypes. 
a

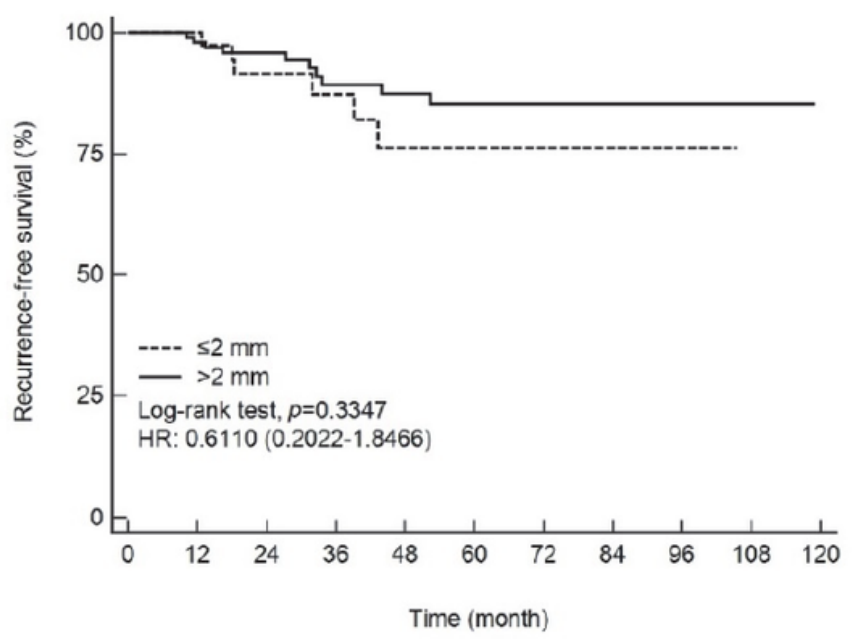

C

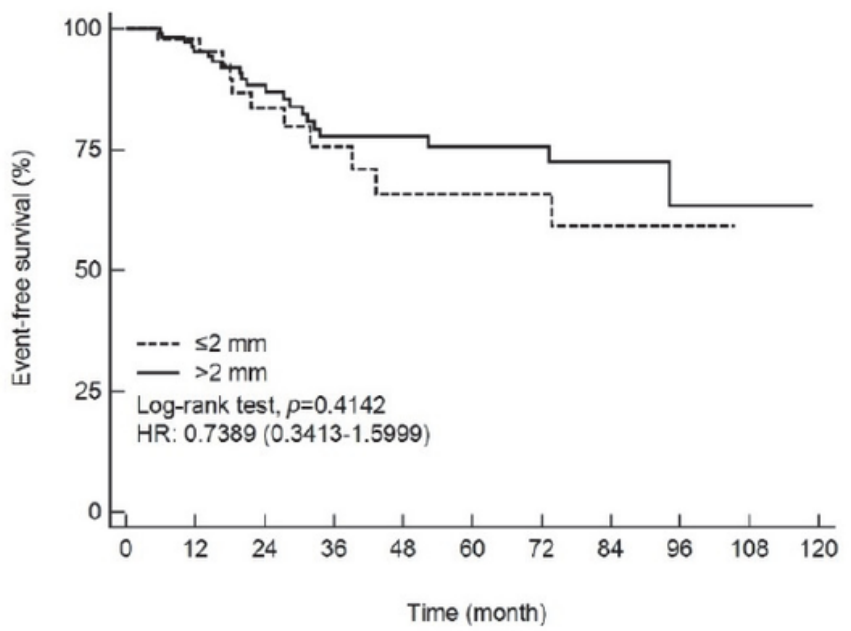

b

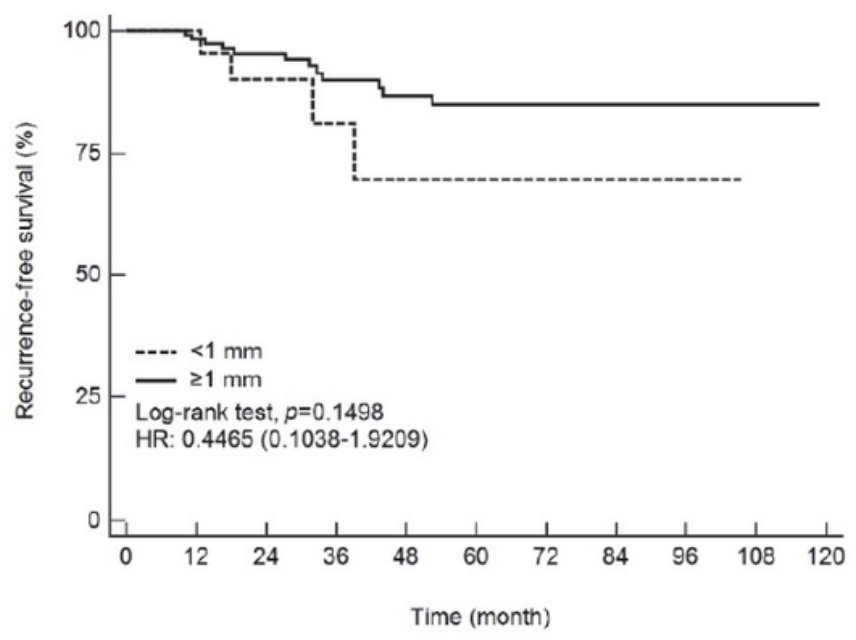

d

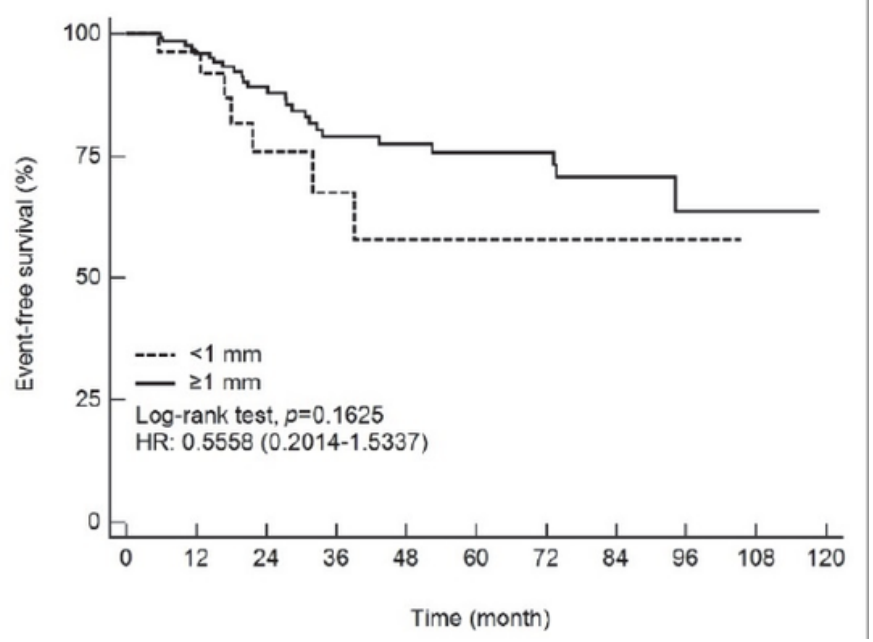

\section{Figure 3}

Kaplan-Meier curves. The results demonstrated the relationship between surgical margins and locoregional recurrence-free survival and event-free survival, respectively. a and $\mathrm{c}, \leq 2 \mathrm{~mm}$ versus $>2 \mathrm{~mm}$. b and $\mathrm{d}_{,}<1 \mathrm{~mm}$ versus $\geq 1 \mathrm{~mm}$. 